\title{
$\mathrm{DC}$ 비접지 급전계통 선택차단형 통합보호계전기 시뮬레이터 개발 및 알고리즘 테스트
}

\section{Development of a Simulator and Algorithm Test for Selective-breaking Integrated Protective Relay for Ungrounded DC Traction Power Supply System}

\author{
안 태 풍 ${ }^{+} \cdot$ 윤 준 석**정 태 영** · 김 인 웅*·정 호 성***
}

(Tae-Pung An $\cdot$ Jun-Seok Yun $\cdot$ Tae-Young Jung $\cdot$ In-Woong Kim $\cdot$ Ho-Sung Jung)

\begin{abstract}
In recent years, a lot of research was done for earth fault protection in ungrounded dc power supply system. As a result, selective-breaking integrated protective relaying system is developed in progress and is currently field-testing are planned. Algorithm on a PC using PSCAD done a lot of testing before performing field tests, but in this study developed algorithms and functions needed to determine whether they were operating normally. Therefore, simulated system is similar to the actual situation was required and made. selective-breaking algorithm verification and validation was performed with simulator.
\end{abstract}

Key Words : Ungrounded dc traction, Protective relay, Selective breaking, Simulator, IEC 61850

\section{1. 서 론}

직류 비접지 계통의 선로보호를 위한 방법은 오래전부터 많은 연구가 진행되어 왔다. 이중에서 지락고장에 대한 보 호방법으로는 지락고장시 대지와 레일간의 과전압을 검출하 여 변전소를 차단하는 방법을 사용하여 왔다. 하지만 이것 은 변전소 급전반 전체를 차단하게 되고 심지어 연락차단에 의해서 여러개소의 변전소가 동시에 차단되는 대규모 정전 이 발생되는것이 현실이었다. 보호관점에서 볼때 고장은 최 소구간만 차단하는 것이 바람직하며, 전철을 사용하는 시민 들의 편의를 고려할 때도 이러한 사항은 더욱 중요해지고 있고 민감한 사항이라 볼 수 있다. 이러한 이유로 현재까지 비접지 $\mathrm{DC}$ 급전계통의 지락고장에 대하여 보호 알고리즘 개발 및 통합보호계전 시스템이 수년간 연구되어 왔다. 이 론적 알고리즘 검증을 위하여 전력계통 과도해석 프로그램 인 $\mathrm{PSCAD}$ 를 사용하여 여러 가지 지락고장 사례들을 모의 하여 왔고, 알고리즘의 검증 및 보완이 진행되어 왔다. 하지 만 이것은 컴퓨터를 이용한 이론적인 알고리즘 검증을 위한 도구로 실계통에 바로 적용하기에는 다소 무리가 있다는 지 적이 제기되어 왔다. 따라서 상업운전을 시행하고 있는 시 스템에 적용하기 위해서는 안전에 대한 검증뿐만 아니라 실 계통과 유사한 모의계통에서 알고리즘 검증이 요구되고 있 다. 본 논문에서는 직류 비접지 급전계통을 모의할 수 있는 하드웨어를 제작하고, 제작된 시뮬레이터를 기반으로 선택지

\footnotetext{
* 정 회 원 : 인텍전기전자(주) 선임연구원

** 정 회 원 : 인텍전기전자(주) 책임연구원

*** 정 회 원 : 한국철도기술연구원 책임연구원

† 교신저자 : 인텍전기전자(주) 상무이사

E-mail : tpan@entecene.co.kr

접수일자 : 2012년 4월 13일

최종완료 : 2012년 5월 10일
}

락차단 알고리즘을 검증을 수행하였다. 이를 통해 제안된 알고리즘 타당성을 입증하였다.

\section{2. 비접지 DC 급전계통 지락고장 선택차단 보호}

\section{1 선택지락차단 보호개요}

그림 1 에서 보여지는 $\mathrm{DC}$ 급전 시스템은 접지를 하지 않 는 비접지방식으로 지락 고장 발생 시에도 고장 전류의 크 기가 작다. 지락 과전압 계전기 $(64 \mathrm{P})[1]$ 는 계전기 내부의 접 지 저항기를 통해 유입된 전류를 이용해 저항기의 전위차 측정 후, 설정된 값과 비교하여 고장 발생 유무를 판단한다. 이 방식은 지락 고장의 여부는 판별할 수 있으나 지락 고장 이 발생한 구간은 판별할 수 없기 때문에 지락 사고 발생 시 사고 구간과 더불어 건전 구간까지 같이 차단되는 특징 이 있다.

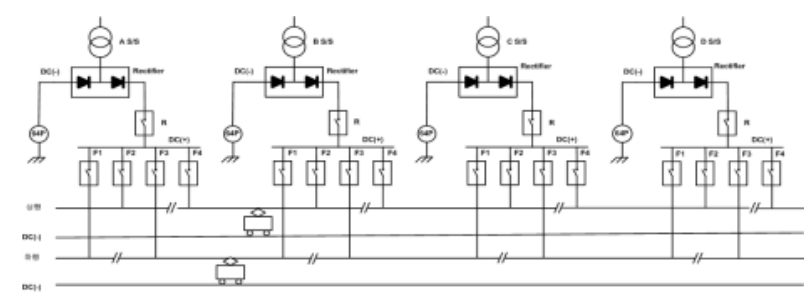

그림 1 도시철도 $\mathrm{DC}$ 급전 시스템

Fig. 1 DC distribution system for subway

선택 지락 보호요소는 이러한 기존의 지락 과전압 계전기 의 단점을 고려하여 지락 고장 발생시 $64 \mathrm{P}$ 계전기가 고장 검출 후 그림 2와 같이 Bypass 회로를 동작 시켜 각 급전 선 전류 증가분을 설정 시간에 적분하여 고장 구간을 판별 하여 고장 구간만을 차단시키기 위한 보호 요소이다. 정상 
운전시 Bypass 회로는 열려 있어 기존의 $\mathrm{DC}$ 급전 시스템과 동일한 상태가 된다. 지락고장 발생 시 지락 과전압 계전기 (64P)가 지락전류를 검출하면 Bypass 회로가 닫힘 상태가 되어 이전의 비 접지에서 접지 시스템으로 변환되어 고장 전류가 급격히 증가 한다. Bypass 회로는[2] 설정 시간 후 에 다시 열림 상태가 되며 이 설정 시간 동안 전류 변화량 이 적분되어[3] Bypass 회로 개방 후 각 피더의 전류 변화 량을 비교하여 변화량이 가장 큰 피더와 전류방향이 고장점 을 향하는 동일한 방향을 갖는 구간을 변전소간 계전기간 통신을 이용하여 선택하게 되고 차단기를 동작시킴으로써 고장 구간만을 차단시킬 수 있다.

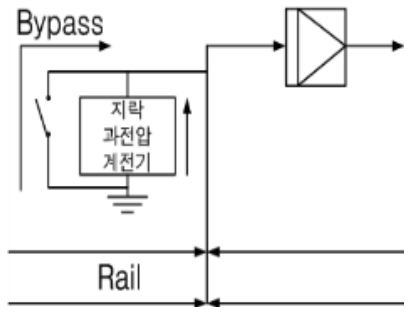

그림 2 접지스위치 Bypass 구성

Fig. 2 Bypass configure for ground switch

\section{2 선택지락 보호 알고리즘}

상기에 기술하였듯이 비접지 $\mathrm{DC}$ 급전계통의 선택지락 차 단 보호는 고장당시의 전류크기와 방향을 계측하여 인근 변 전소와 통신을 통하여 선택차단 알고리즘을 수행하게 된다. 현재 계전기간 통신방법으로는 실시간 통신이 가능한 광통 신을 사용하고 있으며, IEC61850 프로토콜을 사용할 경우 GOOSE 메시지를 사용할 수 있도록 설계되어 있다.

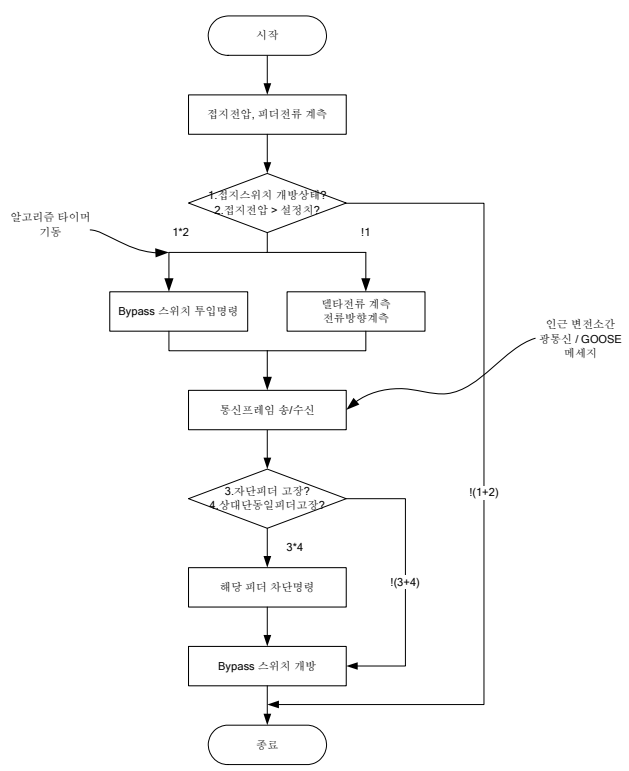

그림 3 선택지락 차단 알고리즘

Fig. 3 Algorithm of selective ground fault

그림 3은 선택지락 차단 알고리즘의 흐름을 간단히 보여 주고 있다. 먼저 접지전압의 검출로써 지락고장 발생을 판
단하고 접지스위치가 개방상태라면 투입을 시켜 비접지 회 로를 접지회로로 변경시킨다. 이때 접지회로의 전환으로 인 해 고장전류가 흐를수 있는 폐회로가 구성되고, 이때 자기 변전소의 각 피더의 전류크기와 방향을 계측한다. 최종적으 로 인근변전소와 통신을 통하여 전류 방향을 비교함으로써 고장구간을 판단하고 차단을 수행하게 된다.

개발된 선택지락차단 알고리즘의 중요한 고려사항으로 접 지스위치의 투입시간차 및 계전기간 통신지연 등 다양한 사 항이 있으며 선택지락차단 알고리즘은 이러한 여러 가지의 경우를 고려하여 설계되었다.

\section{3. 시뮬레이터 개발 및 알고리즘 테스트}

\section{1 시뮬레이터 개발}

선택차단형 통합보호시스템을 현장에 적용하기 전에 가능 한 현장과 유사한 모의 시스템을 개발하여 알고리즘 테스트 및 현장적용 가능성을 검증할 수 있는 시뮬레이터의 필요성 이 요구 되었고 이와같은 필요성에 의하여 비접지 $\mathrm{DC}$ 급전 계통 시뮬레이터를 제작하게 되었다. 제작된 시뮬레이터는 비접지 $\mathrm{DC}$ 급전계통을 대상으로 제작되었으며, 3 개의 변전소 로 모의 구성하였다. 시스템 전압은 모의시스템에 맞도록 $\mathrm{DC} 5 \mathrm{~V}$ 를 사용하였고, 선로 임피던스, 전동차 부하, 고장점 저항, 고장종류등은 모듈교체만으로 다양한 시험이 가능하도 록 가변형으로 개발하였다. 개발된 시뮬레이터의 세부사양 은 표 2 과 같다.

\section{표 $1 \mathrm{DC}$ 급전계통 시뮬레이터 구성 사양}

Table 1 Spec. of dc traction power system simulator

\begin{tabular}{|c|c|c|}
\hline \multicolumn{2}{|c|}{ 변전소 전압 레벨 } & $5 \mathrm{Vdc}$ \\
\hline \multicolumn{2}{|c|}{ 변전소 개수 } & 3개소 \\
\hline \multicolumn{2}{|c|}{ 변전소 임피던스 } & $0.5 \Omega$ \\
\hline \multicolumn{2}{|c|}{ 급전방식 } & 상행/하행 병렬급전 \\
\hline \multicolumn{2}{|c|}{ 통합보호계전기 } & 변전소별 1대 \\
\hline \multicolumn{2}{|c|}{ 변전소 통신 매체 } & 광케이블 \\
\hline \multicolumn{2}{|c|}{ 접지스위치 } & DI 입력제어 / 수동조작 \\
\hline \multirow{2}{*}{$\begin{array}{l}\text { 선로 } \\
\text { 임피던스 }\end{array}$} & 저항 & $0 \Omega / 2 \Omega$ 가변선택 \\
\hline & 인덕턴스 & $100 \mathrm{mH}$ \\
\hline \multirow{3}{*}{ 계측센서 } & 피더전압 & TD 1000:1mA \\
\hline & 피더전류 & TD 1000:1mA \\
\hline & 접지전압 & TD 1000:1mA \\
\hline \multirow{2}{*}{ 전차부하 } & 회선 & 상행 1대, 하행 1대 가능 \\
\hline & 부하종류 & $50 \Omega$ \\
\hline \multicolumn{2}{|c|}{ 조작 스위치 및 버튼 } & $\begin{array}{l}\text { 고장선택, 부하선택, } \\
\text { 접지조작, 피더별 차단기 조작 }\end{array}$ \\
\hline \multicolumn{2}{|l|}{ 상태램프 } & 피더반별 차단기 접점상태 \\
\hline \multirow{2}{*}{ 고장 } & 조작방식 & 수동조작, 상행/하행 개별 \\
\hline & 저항 & $5 \Omega$ \\
\hline
\end{tabular}

그림 4는 비접지 $\mathrm{DC}$ 급전계통 시뮬레이터의 전기적 회로 를 보여주고 있다. 지락고장 모의시 지락전류는 접지전압 검출용 저항을 통해서 흐르고 이때 검출된 전압을 판단하여 통합보호계전기에서 디지털 출력접점을 통하여 접지스위치 투입명령을 송신한다. 접지스위치가 투입되면 고장전류는 접지회로를 통하여 회로 전반에 흐르게 된다. 통합보호계전 기는 이때 선택지락 알고리즘을 수행하고 최종적으로 계전 
기간 통신을 통하여 선택차단 명령을 해당 급전반 차단기로 명령을 송신하게 된다. 시뮬레이터는 병렬급전을 고려하여 상행/하행을 구분하여 각각 지락고장 모의가 가능하도록 설 계 및 제작되었다.

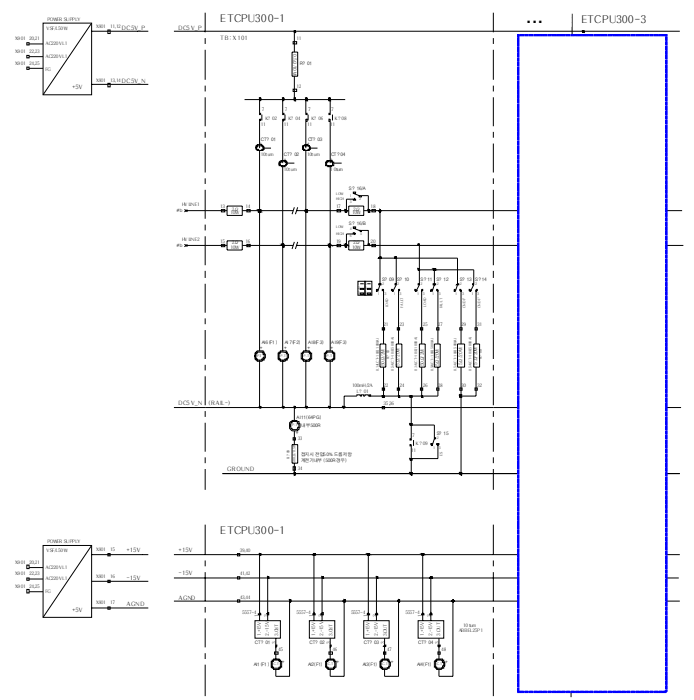

그림 4 선택차단 시뮬레이터 도면

Fig. 4 Electric drawing of dc simulator

선택차단형 통합보호계전기는 시뮬레이터의 구성 변전소 별로 1 대씩 장착되었으며, 계전기들은 선택지락 알고리즘을 위하여 광통신망을 이용하여 변전소간 통신을 수행되도록 설계 및 제작되었다. 실시간 고속도 통신을 위하여 현재 광 통신을 사용하나 IEC61850의 GOOSE[4][5] 메시지를 사용할 경우 이더넷도 사용할 수 있도록 구성되어 있다. 그림 5는 제작된 비접지 $\mathrm{DC}$ 급전계통 시뮬레이터의 형상을 보여주고 있다.

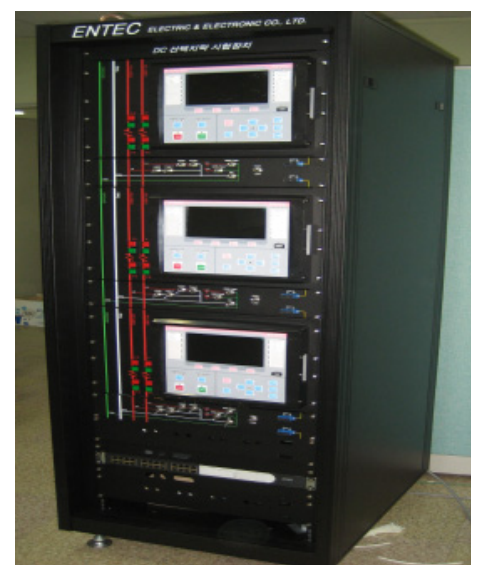

그림 5 선택차단 시뮬레이터

Fig. 5 selective ground simulator

\section{2 선택차단형 통합보호계전기}

통합보호계전기는 기존의 급전반에 개별적으로 설치되어 사용되고 있던 보호계전기의 기능과 선택지락 차단 기능을
포함한 구조로 설계 및 제작되었다. 선택지락 알고리즘 특 성상 모든 급전반의 전류와 접지전압을 사용하기 때문에 통 합보호계전기는 기존 계전기와는 달리 하나의 계전기로 통 합기능을 구현할 수 있으며, 모든기능을 수행하기 위해서 고 성능의 마이크로 프로세서를 사용하고 있다. 그림 6은 통합 계전기의 구성에 대한 블록도를 보여주고 있다. 기능에 따 라 8개의 모듈로 구성되어 있다. 전원모듈은 변전소 전원에 상황에 맞게 $110 / 220 \mathrm{~V}$ 로 선택적으로 사용할 수 있게끔 설계 되었다. DSP 모듈은 Analog Input 모듈에서 전압 및 전류 신호를 입력받아 보호요소에 필요한 데이터로 연산하여 보 호관련 알고리즘을 수행한다. 통신모듈은 현재 가장 일반적 으로 사용되는 DNP3프로토콜과 변전소 프로토콜로 자리잡 고 있는 IEC60870등을 지원할 수 있는 구조로 설계되었다. Main 모듈은 사용자와 $\mathrm{HMI}$ 모듈과의 인터페이스 담당 및 이력, 설정, PLC등 모든 데이터 베이스 관련 처리를 수행하 도록 설계되었다.

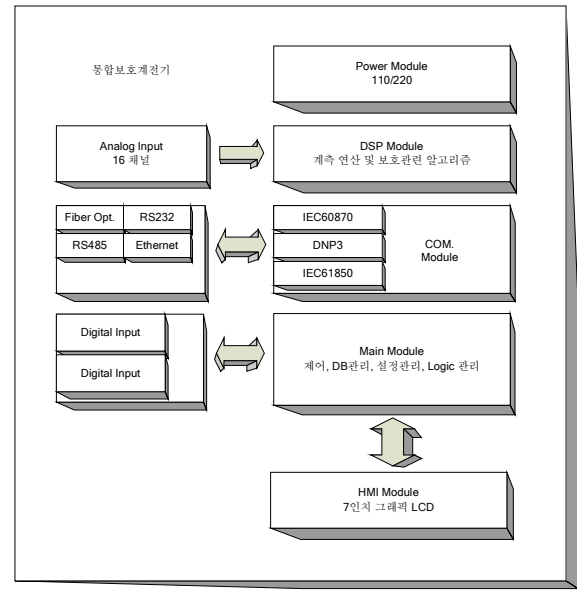

그림 6 통합보호계전기 기능 블록도

Fig. 6 Block diagram of protective relay

제작된 통합보호계전기의 형상은 그림 7에서 보여주고 있 으며 7 인치 그래픽 $\mathrm{LCD}$ 를 사용하여 사용자가 현장에서 설 정 및 이력확인, 단선도 보기등 시각적인 부분에 많은 편의 성을 갖도록 설계 및 제작 하였다.

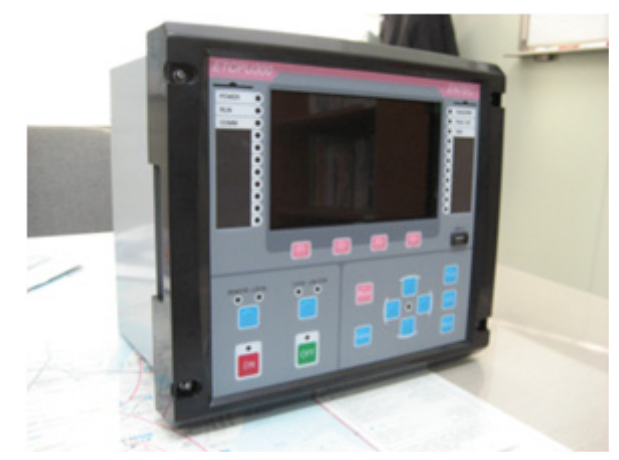

그림 7 통합보호계전기

Fig. 7 Integrated protective relay

통합보호계전기의 주요사양은 표 3와 같으며, 급전반 보 호에 사용되는 기존 계전기의 일반적인 보호요소 $(76 \mathrm{D}, 50 \mathrm{~F}$, 
$85 \mathrm{~F}, 80 \mathrm{~F}, 45 \mathrm{~F}, \mathrm{DV}, 26 \mathrm{~F}$ )와 더불어 지락고장에 대한 보호연 구의 결과인 선택지락 차단 기능이 포함되어 있다.

\section{표 2 통합보호계전기 주요사양}

Table 2 Features of integrated protective relay

\begin{tabular}{|c|c|c|c|c|}
\hline \multirow{9}{*}{$\begin{array}{l}\text { 보호 } \\
\text { 기능 }\end{array}$} & \multirow[b]{3}{*}{$\begin{array}{l}\text { 과전류 } \\
\text { 보호요소 }\end{array}$} & \multirow{2}{*}{$\begin{array}{l}\text { 정한시 } \\
\text { 직류과전류 } \\
\text { 보호요소 } \\
\text { (76D) }\end{array}$} & $\begin{array}{l}\text { Positive } \\
\text { 요소 }\end{array}$ & $\begin{array}{l}\text { 동작전류정정치 : } 1,000 \mathrm{~A} \sim 10,000 \mathrm{~A} \\
\text { 정한시 (INST, } 0.05 \mathrm{~s} \sim 300 \mathrm{~s} \text { ) }\end{array}$ \\
\hline & & & $\begin{array}{c}\text { Negative } \\
\text { 요소 }\end{array}$ & $\begin{array}{l}\text { 동작전류정정치 : }-1,000 \mathrm{~A} \sim-10,000 \mathrm{~A} \\
\text { 정한시 (INST, } 0.05 \mathrm{~s} \sim 300 \mathrm{~s} \text { ) }\end{array}$ \\
\hline & & \multicolumn{2}{|c|}{$\begin{array}{l}\text { 직류고장검출요소 } \\
\text { (50F) }\end{array}$} & $\begin{array}{l}\text { Delta I 동작 전류치 : } 1,000 \mathrm{~A} \sim 10,000 \mathrm{~A} \\
\text { Delta I 경보 전류치 : } 1,000 \mathrm{~A} \sim 10,000 \mathrm{~A} \\
\text { Delta I 지연시간 : } 0 \sim 600 \mathrm{~ms} \\
\text { Delta I 리셋시간 : } 0 \sim 60.0 \mathrm{~ms} \\
\text { DI/DT 초기기울기 : } 1.00 \mathrm{kA} / \mathrm{s} \sim 99.00 \mathrm{kA} / \mathrm{s} \\
\text { DI/DT 최종기울기 : }: 1.00 \mathrm{kA} / \mathrm{s} \sim 99.00 \mathrm{kA} / \mathrm{s} \\
\text { DI/DT 지연시간 }: 0 \sim 600 \mathrm{~ms} \\
\text { DI/DT 최소동작 전류치 : } 100 \mathrm{~A} \sim 10,000 \mathrm{~A}\end{array}$ \\
\hline & $\begin{array}{l}\text { 연락차단 } \\
\text { 보호요소 }\end{array}$ & \multicolumn{2}{|c|}{$85 \mathrm{~F}$} & 순시 (30ms 이내) \\
\hline & $\begin{array}{l}\text { 부족전압 } \\
\text { 보호요소 }\end{array}$ & \multicolumn{2}{|c|}{$80 \mathrm{~F}$} & $\begin{array}{l}\text { 동작전압치 정정 : } 100 \mathrm{~V} \sim 2,000 \mathrm{~V} \\
\text { 정한시 }(0 \sim 600 \mathrm{~s})\end{array}$ \\
\hline & $\begin{array}{l}\text { 과전압 } \\
\text { 보호요소 }\end{array}$ & \multicolumn{2}{|c|}{$45 \mathrm{~F}$} & $\begin{array}{l}\text { 동작전압치 정정 : } 100 \mathrm{~V} \sim 2,000 \mathrm{~V} \\
\text { 정한시 }(0 \sim 600 \mathrm{~s})\end{array}$ \\
\hline & $\begin{array}{l}\text { 차전압 } \\
\text { 보호요소 }\end{array}$ & \multicolumn{2}{|c|}{ DV } & $\begin{array}{l}\text { 동작전압치 정정 : } 0 \mathrm{~V} \sim 2,000 \mathrm{~V} \\
\text { 정한시 }(0 \sim 600 \mathrm{~s})\end{array}$ \\
\hline & $\begin{array}{l}\text { 열적 } \\
\text { 보호요소 }\end{array}$ & \multicolumn{2}{|c|}{$26 \mathrm{~F}$} & $\begin{array}{l}\text { 정격전류치 정정 : } 1,000 \mathrm{~A} \sim 10,000 \mathrm{~A} \\
\text { 연속전류시간 : } 1 \sim 6,000 \mathrm{~min} \\
\text { Trip Level 정정 : } 50.0 \% \sim 130.0 \% \\
\text { Alarm Level 정정 : } 50.0 \% \sim 100.0 \%\end{array}$ \\
\hline & $\begin{array}{l}\text { 선택지락 } \\
\text { 차단 }\end{array}$ & \multicolumn{2}{|r|}{ - } & $\begin{array}{l}\text { 지락전압검출 : } 1 \mathrm{~V} \sim 1,000 \mathrm{~V} \\
\text { 지락과전류 : } 1 \mathrm{~A} \sim 60,000 \mathrm{~A}\end{array}$ \\
\hline \multicolumn{4}{|c|}{ 제어전원 } & DC $110 \mathrm{~V}(70 \mathrm{~V} \sim 121 \mathrm{~V})$ \\
\hline \multicolumn{4}{|c|}{ 통신기능 } & RS232C / RS485 / Ethernet \\
\hline \multicolumn{4}{|c|}{ 출력 } & $\begin{array}{l}\text { 로직 구성 가능한 출력 } \\
\text { Trip용 : } 6 \text { 개 } \\
\text { 신호용 : } 14 \text { 개 }\end{array}$ \\
\hline \multicolumn{4}{|c|}{ 입력 } & 로직 구성 가능한 입력 24개 \\
\hline
\end{tabular}

\section{3 선택차단 알고리즘 테스트}

개발된 시뮬레이터를 사용해 지락고장에 대한 선택차단 알고리즘을 구현하였다. 고장사례 구성 및 데이터는 그림 8 과 표 3 과 같다.

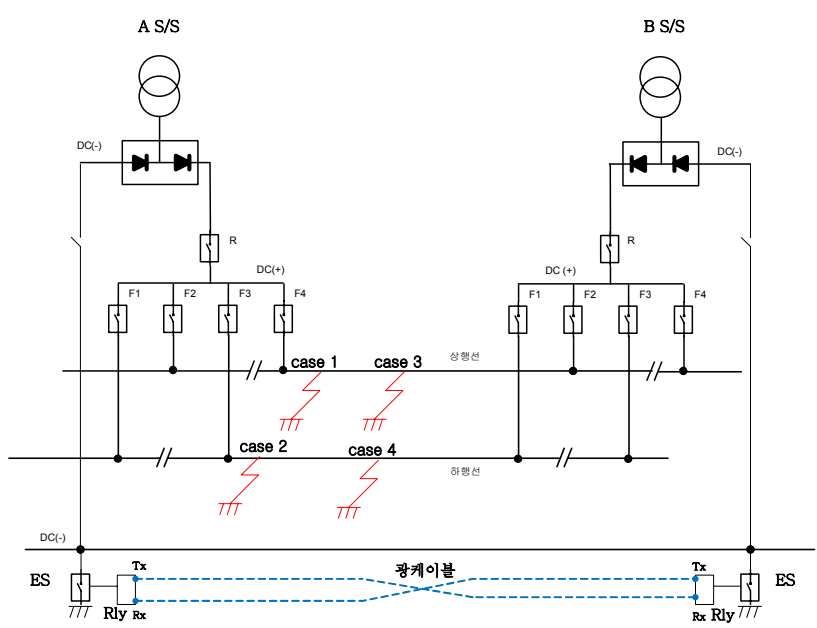

그림 8 시뮬레이터 지락고장모의 사례

Fig. 8 Case of ground fault of simulator

case1은 A 변전소 상행선 인근지점의 지락고장이며, case2는 A 변전소 하행선 인근지점의 지락고장을 나타내고 있다. case3은 $\mathrm{A}$ 변전소와 $\mathrm{B}$ 변전소 상행선 중간지점의 지
락고장이며, case4는 A 변전소와 B 변전소 하행선 중간지점 의 지락고장을 나타내고 있다. 개발된 선택차단 알고리즘은 고장위치에 관계없이 상행선의 지락고장시 $\mathrm{A}$ 변전소의 $\mathrm{F} 4$ 와 $\mathrm{B}$ 변전소의 $\mathrm{F} 2$ 만 차단되어야 하며, 하행선의 지락고장시 $\mathrm{A}$ 변전소의 F3과 B변전소의 F1만 차단되어야 한다.

\section{표 3 시뮬레이터 지락고장 모의 데이터}

Table 3 Data of ground fault of simulator

\begin{tabular}{|c|c|c|c|}
\hline \multicolumn{2}{|r|}{ 지락고장사례 } & \multicolumn{2}{|c|}{ 시뮬레이터구성(고장점 58) } \\
\hline \multirow{2}{*}{ case 1} & \multirow{2}{*}{ A S/S F4 인근 } & A S/S 선로저항 & $0 \Omega$ \\
\hline & & $\mathrm{B} \mathrm{S} / \mathrm{S}$ 선로저항 & $2 \Omega$ \\
\hline \multirow{2}{*}{ case 2} & \multirow{2}{*}{ A S/S F3 인근 } & $\mathrm{A} \mathrm{S} / \mathrm{S}$ 선로저항 & $0 \Omega$ \\
\hline & & $\mathrm{B} \mathrm{S} / \mathrm{S}$ 선로저항 & $2 \Omega$ \\
\hline \multirow{2}{*}{ case3 } & \multirow{2}{*}{ A S/S F4 B S/S F2 } & $\mathrm{A} \mathrm{S} / \mathrm{S}$ 선로저항 & $2 \Omega$ \\
\hline & & $\mathrm{B} \mathrm{S} / \mathrm{S}$ 선로저항 & $2 \Omega$ \\
\hline \multirow{2}{*}{ case 4} & \multirow{2}{*}{ A S/S F3 B S/S F1 } & $\mathrm{A} \mathrm{S} / \mathrm{S}$ 선로저항 & $2 \Omega$ \\
\hline & & $\mathrm{B} \mathrm{S} / \mathrm{S}$ 선로저항 & $2 \Omega$ \\
\hline
\end{tabular}

그림 9 에서 16 은 결과파형을 보여주고 있다. 공통적으로 지락고장 발생시 지락(접지)전압은 순간적으로 크게 증가하 였으며, 접지스위치 투입시점에서 고장전류가 급격히 상승함 을 보였다. 이후 양측 변전소의 고장구간에 해당되는 차단 기가 약간의 시간차를 두고 차단되었다. 이것은 계전기간 통 신에 의한 차단지연시간에 해당된다. 접지전압은 이론상 접 지스위치 투입즉시 영전위로 떨어져야 하나 그렇치는 않았 으며, 이것은 시뮬레이터의 구성상 누설전류에 의한 전압상 승으로 판단된다. case1과 case2의 차단시간은 case3과 case4의 경우보다 상대적으로 많이 소요되었다. 이것은 알고 리즘 특성에 기인한 것으로써 전류의 크기와 기울기에 관계 된다. 결과적으로 시뮬레이터를 이용한 고장모의는 고장위치 에 따라 알고리즘의 수행시간에 차이가 발생하나 모든 사례 에서 선택차단 알고리즘이 정상 동작됨을 확인할 수 있었다.

첫 번째 시험결과로 casel의 경우 $\mathrm{A}$ 변전소의 $\mathrm{F} 4$ 와 $\mathrm{B}$ 변전소의 $\mathrm{F} 2$ 급전반 차단기가 동작하는 것을 확인하였고, 이때 계측된 전류 및 전압파형은 그림 9,10 과 같다.

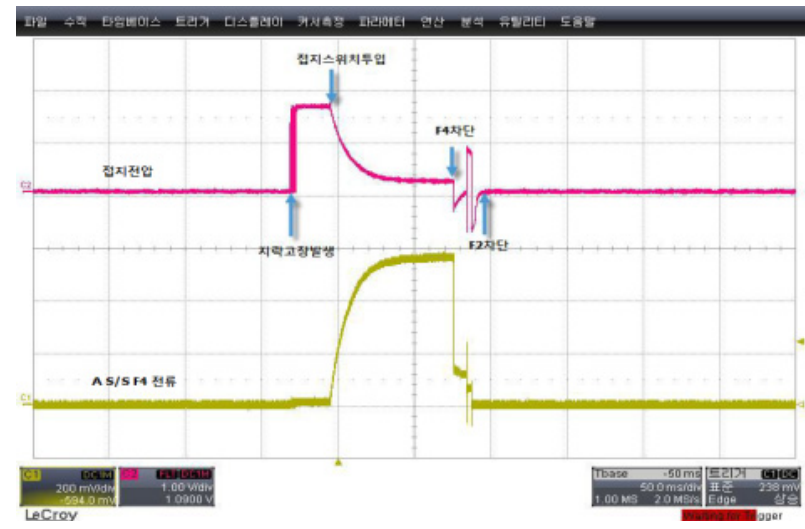

그림 9 case1 A S/S F4 전류 $(\mathrm{CH} 1)$ 및 접지전압 $(\mathrm{CH} 2)$

Fig. 9 Current $(\mathrm{CH} 1)$ of $\mathrm{F} 4$ and ground voltage $(\mathrm{CH} 2)$ of $A$ $\mathrm{S} / \mathrm{S}$ in case 1 


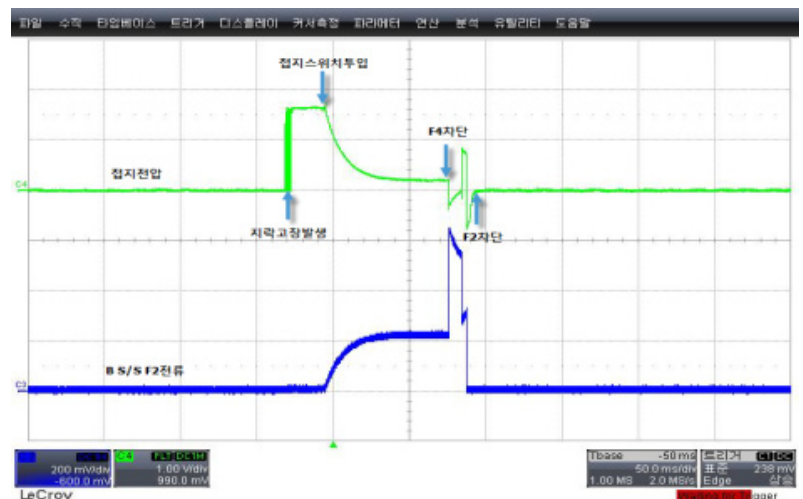

그림 10 case $1 \mathrm{~B} \mathrm{~S} / \mathrm{S}$ F2 전류 $(\mathrm{CH} 3)$ 및 접지전압 $(\mathrm{CH} 4)$

Fig. 10 Current $(\mathrm{CH} 3)$ of $\mathrm{F} 2$ and ground voltage $(\mathrm{CH} 4)$ of $\mathrm{B}$ $\mathrm{S} / \mathrm{S}$ in case 1

두 번째 시험결과로 case2의 경우 $\mathrm{A}$ 변전소의 F3와 B 변전소의 $\mathrm{F} 1$ 급전반 차단기가 동작하는 것을 확인하였고, 이때 계측된 전류 및 전압파형은 그림 11,12 와 같다.

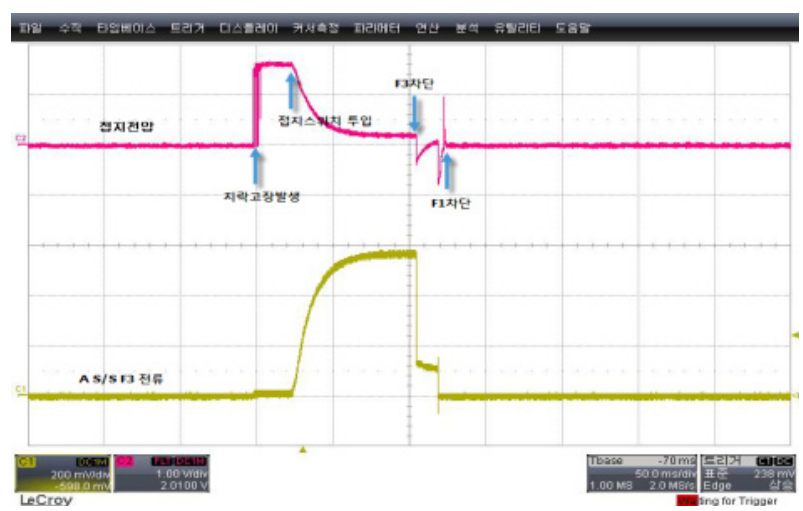

그림 11 case2 A S/S F3 전류 $(\mathrm{CH} 1)$ 및 접지전압 $(\mathrm{CH} 2)$

Fig. 11 Current $(\mathrm{CH} 1)$ of $\mathrm{F} 3$ and ground voltage $(\mathrm{CH} 2)$ of $A$ $\mathrm{S} / \mathrm{S}$ in case2

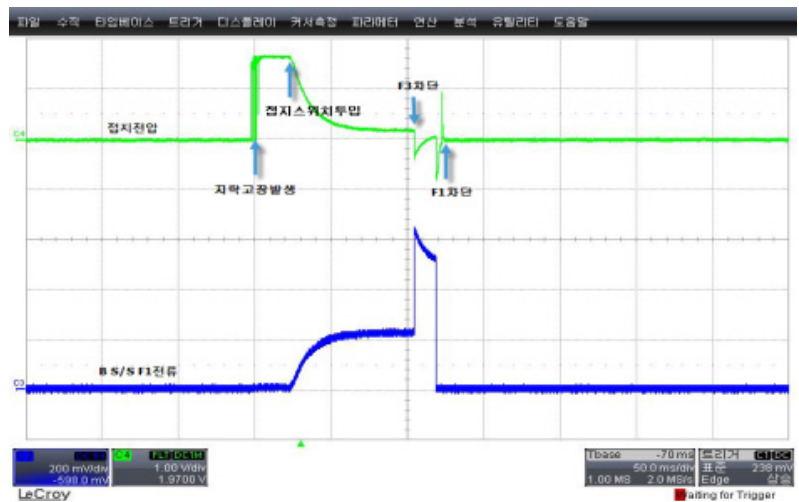

그림 12 case2 B S/S F1 전류 $(\mathrm{CH} 3)$ 및 접지전압 $(\mathrm{CH} 4)$

Fig. 12 Current $(\mathrm{CH} 3)$ of $\mathrm{F} 1$ and ground voltage $(\mathrm{CH} 4)$ of $A$ $\mathrm{S} / \mathrm{S}$ in case 1

세 번째 시험결과로 case 3 의 경우 $\mathrm{A}$ 변전소의 $\mathrm{F} 4$ 와 $\mathrm{B}$ 변전소의 $\mathrm{F} 2$ 급전반 차단기가 동작하는 것을 확인하였고,
이때 계측된 전류 및 전압파형은 그림 13,15 와 같다.

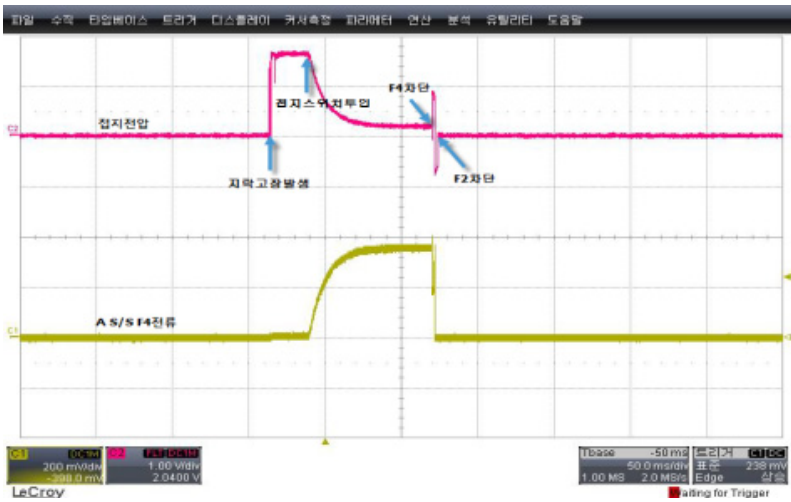

그림 13 case3 A S/S F4 전류 $(\mathrm{CH} 1)$ 및 접지전압 $(\mathrm{CH} 2)$

Fig. 13 Current $(\mathrm{CH} 1)$ of $\mathrm{F} 4$ and ground voltage $(\mathrm{CH} 2)$ of $A$ $\mathrm{S} / \mathrm{S}$ in case3

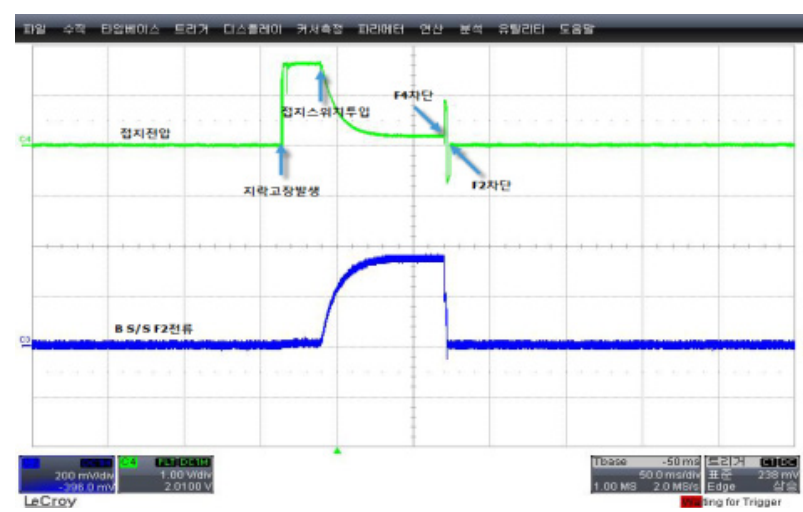

그림 14 case3 B S/S F2 전류 $(\mathrm{CH} 3)$ 및 접지전압 $(\mathrm{CH} 4)$

Fig. 14 Current $(\mathrm{CH} 3)$ of $\mathrm{F} 2$ and ground voltage $(\mathrm{CH} 4)$ of $\mathrm{B}$ $\mathrm{S} / \mathrm{S}$ in case 3

네 번째 시험결과로 case 4 의 경우 A 변전소의 F3와 B 변전소의 $\mathrm{F} 1$ 급전반 차단기가 동작하는 것을 확인하였고, 이때 계측된 전류 및 전압파형은 그림 16,17 과 같다.

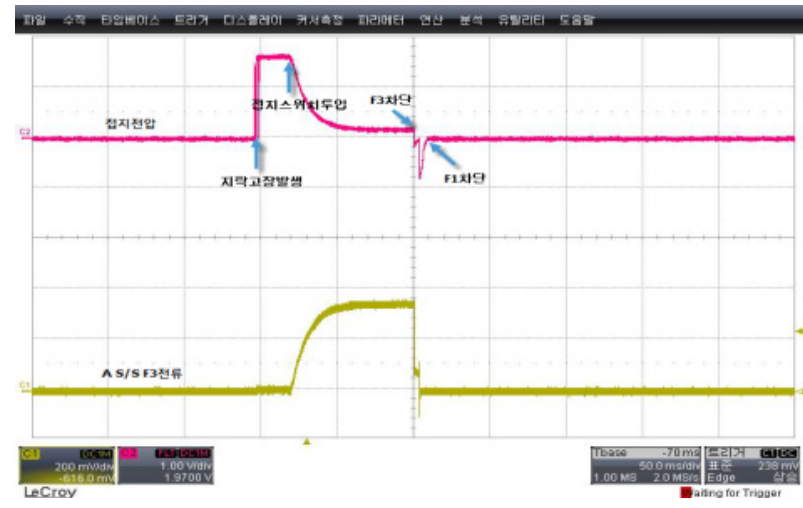

그림 15 case4 A S/S F3 전류 $(\mathrm{CH} 1)$ 및 접지전압 $(\mathrm{CH} 2)$

Fig. 15 Current $(\mathrm{CH} 1)$ of $\mathrm{F} 3$ and ground voltage $(\mathrm{CH} 2)$ of $A$ $\mathrm{S} / \mathrm{S}$ in case4 


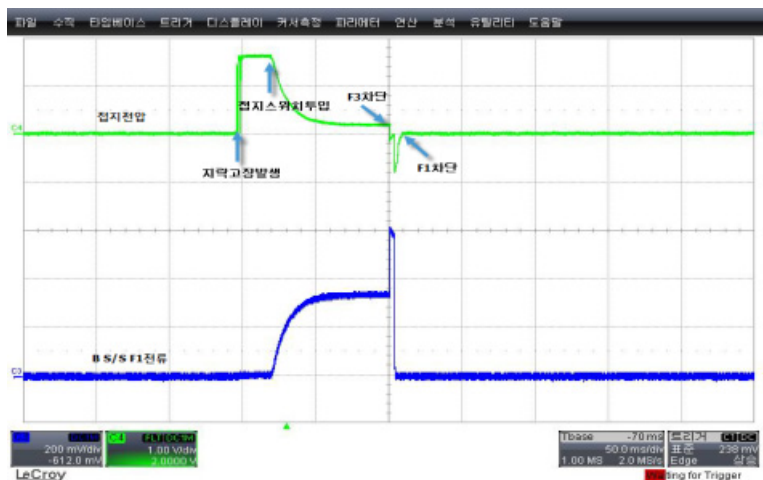

그림 16 case4 B S/S F1 전류 $(\mathrm{CH} 3)$ 및 접지전압 $(\mathrm{CH} 4)$

Fig. 16 Current $(\mathrm{CH} 3)$ of $\mathrm{F} 1$ and ground voltage $(\mathrm{CH} 4)$ of $\mathrm{B}$ $\mathrm{S} / \mathrm{S}$ in case 4

\section{4. 결 론}

논문에서는 비접지 $\mathrm{DC}$ 급전계통 선택차단형 통합보호계 전 시스템을 검증하기 위하여 시뮬레이터 개발에 대한 내용 을 기술하였으며, 시뮬레이터를 이용한 선택지락 알고리즘 검증 테스트를 수행하였다. 개발된 시률레이터는 선택지락 차단 알고리즘 검증뿐만 아니라 다양한 고장에 대해서 검증 할 수 있었고, 선택지락차단 알고리즘과 제작된 계전기의 동 작이 모두 정상적임을 판단할 수 있었다. 또한 제작된 시뮬 레이터는 실계통을 염두해 두고 제작되었기 때문에 현장실 증에 본 선택지락차단 시스템이 충분히 적용될 수 있음을 확인할 수 있었다. 향후 연구방향으로 시스템의 실계통 적 용과 현장시험을 통한 실제 알고리즘의 동작여부와 관련 데 이터의 취득 및 분석을 수행할 예정이다.

\section{감사의 글}

본 연구는 국토해양부 도시철도표준화2단계연구개 발사업의 연구비지원(07도시철도표준화A01)에 의해 수행되었습니다.

\section{참 고 문 헌}

[1] Hyun-Ki Jung et al, "A Study on Operational Characteristics of DC protective relay systems on the Subway', Annual Spring Conference of the Korean Society for Railway, pp451-465, 2008.

[2] Sang-Hee Kang et al, "Integrated Protection Method for DC Railway System", KIEE, vol.60, no.2, pp285-292, 2011. 2.

[3] Chang-Young Choi et al, "Selective Ground Fault Protection Algorithm Using a Cumulative Overcurrent Element for DC Railway System”, KIEE Annual Spring Conference,, pp55-57, 2009. 5.

[4] IEC, IEC 61850 International Standard Part1-9. 2003.

[5] Tae-Young Jung et al, "Design of IEC 61850 Logical Node for modeling protective elements of selective-breaking integrated protective relay for DC traction power suply system", KIEE, vol.61, no.3, pp491-496, 2012. 3

저 자 소 개

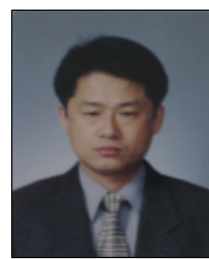

\section{안 태 풍 (安 泰 豊)}

1992년 2월 성균관대학교 전자공학과 졸 업(공학사), 1992년 2월 1996년 5월 일 진전기공업(주) 기술연구소. 1996년 6월 현재 인텍전기전자(주) 기술연구소 상무 이사

Tel : 031-299-8410

Fax : 031-299-8401

E-mail : tpan@entecene.co.kr

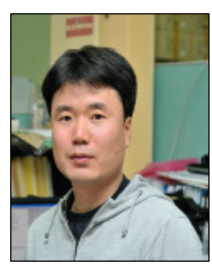

\section{윤 준 석 (尹 晙 碩)}

1976년 5월생, 2004년 명지대학교 전기공 학과 졸업(공학석사), 2004년 1월 현재 인텍전기전자(주) 전력전자시스템 연구소 선임연구원

Tel : 031-299-8413

Fax : 031-299-8401

E-mail : jsyun@entecene.co.kr

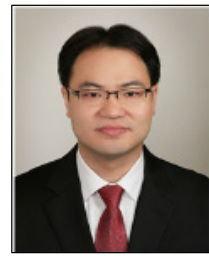

\section{정 태 영 (鄭 邰 榮)}

1972년생, 1999년 명지대학교 기계공학과 졸업(공학석사), 2008년 University of Washington 기계공학과 졸업(공학박사). 2009 현재 인텍전기전자(주) 전력전자시 스템 연구소 책임 연구원

Tel : 031-299-8418

Fax : 031-299-8401

E-mail : tyjung@entecene.co.kr

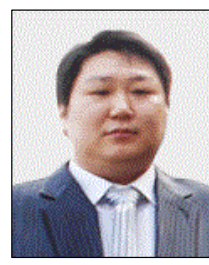

\section{김 인 웅 (金 仁 雄)}

1980년 6월생, 2009년 명지대학교 전기공 학과 졸업(공학석사), 2009년 2월 현재 인텍전기전자(주) 전력전자시스템 연구소 주임연구원

Tel 031-299-8416

Fax 031-299-8401

E-mail：iwkim@entecene.co.kr

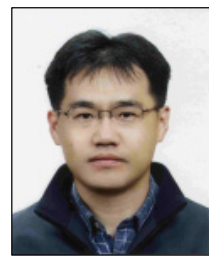

\section{정 호 성 (鄭 澔 聖)}

1971년생. 1998년 성균관대학교 전기공학 과 졸업(공학석사). 2002년 성균관대학교 전기전자 및 컴퓨터공학부 졸업(공학박 사). 2002년 현재 한국철도기술연구원 광역도시철도 연구본부 선임연구원

Tel : 031-460-5116

Fax : 031-460-5459

E-mail : hsjung@krri.re.kr 